\title{
STUDENTS AWARENESS AND UTILIZATION OF EDUCATIONAL BROADCASTS TO LEARN IN OGBOMOSO, OYO STATE NIGERIA
}

\author{
Dr. Charles Olubode OLUMORIN \\ Department of Educational Technology \\ University of Ilorin \\ Ilorin, Nigeria \\ Musiliu Adekola ADEROJU \\ Department of Educational Technology \\ University of Ilorin \\ Ilorin, Nigeria \\ Amos Ochayi ONOJAH \\ Department of Educational Technology \\ University of Ilorin \\ Ilorin, Nigeria
}

\section{ABSTRACT}

Radio and Television are broadcast media meant to disseminate audio and video signal, messages, information or programs to wide range of audience. Radio and television are already playing a role in educating the populace non-formally through various educational channels and programs, but there is significant potential to capitalize on their ability to enhance development and learning curriculum content among secondary school students. This study: 1) Find out the awareness of educational radio and television programs by secondary school students in Ogbomoso 2 ) Investigate secondary school students access to educational radio and television programs in Ogbomoso and 3) Investigate problems militating against students' use of educational radio and television programs for learning. Questionnaire was used as instrument to elicit responses from 100 secondary school students on their awareness-on and access to seven educational radio and television programs. The findings revealed that the students were not aware of the educational radio and television programs even though they have access to it. The study recommends that teachers in secondary schools should include educational broadcasts as forms of stimulus variation that they could apply to their classes and educational programs producers on both radio and television should create enough awareness about the programs to enable students follow the programs at appropriate time.

Keywords: Educational radio and television programs, Multichoice (DSTV), Startimes, educational broadcasts.

\section{INTRODUCTION}

Modern technology has transformed the way students learn and interact with their environment. Radio and Television are broadcast media meant to disseminate audio and video signal, messages, information or programs to wide range of audience. Broadcast media are regarded as eye and hear of the people because they look for information on behalf of the general public. Media have always formed an important part of modern education since the beginning of the twentieth century. From print to radio, television, and today's Web-enabled e-learning, each medium has been seen as a potential solution for the problems, inadequacies and certain ills of education. Invariably, the purpose of inducting 
media into education has been two-fold: to increase the reach and thereby access; and to enrich the quality of educational content. The birth of a new medium has not however, supplanted the previous one; since each has found its own niche.

Broadcast media on its own help the populace to be conscious and aware of various events near and far away from them. Radio and television are now inseparable with the society because of the numerous roles they play including educational function. Educational broadcasting refers to television programming and radio programming providing or related to courses of study. The term "educational" is also applied at times to other programs that are particularly enlightening, informative or intellectually stimulating. Educational broadcast is the term given to the medium's use in formal learning systems, whether primary or higher education (Berman, 2008). It is typically used as a means for course material delivery, and often integrated with various kinds of interaction: for example, in classrooms, discussion groups, or via the telephone. Community radio, on the other hand, involves informal learning processes whereby communities plan, own, and operate their own radio stations. The informal learning topics of community radio typically include child nutrition, family planning, and agricultural tips. Community radio necessarily involves a non-profit enterprise, community ownership and participation, and usually a participatory approach to learning.

Wherever the mass media have been established, education has been put at the forefront of the fruits to be reaped or as on objective for the development of the mass media. Since education has been linked to the creation of communication systems that can reach wide populations, educational broadcasting has been identified with development and nation building. However, they are powerful socializing agents to reach large heterogeneous and widely dispersed audience. It is observed that millions of people over huge areas can be reached very quickly via radio and television by spreading news, information, entertainment and so on. Indeed, they represent powerful tools of socializing people and students in particular through their different educative programs which increase the level of literacy in the society.

Sambo (2012) noted that broadcast media are tools that invest the past with an air of reality. They provide the learners with realistic experience, which capture their attention and help in the understanding of the historical phenomena. They appeal to the mind through the visual auditory senses. Also, Ortyoyande (2006) noted that we receive knowledge through our senses; they also noted that if we hear we forget, if we see we remember, and if we do something we know it. So, access to educational radio and television makes learning process more effective and productive. Also, those educational programs can be recorded to benefit Learners by listening and viewing the lesson programs severally, hence aids their retention. Therefore, educational radio and television encourage learning, make it easier and interesting.

It should be noted that radio and television can effectively be utilized to teach individual or public the norms and values of society and reinforce same. Recent development in television has drastically affected educational procedure for improved quality of education offered to students. Television resource in instructional delivery will serve dual purposes and more efficient classroom instruction (Onabajo, 2000). The advancement which radio and television offer in education can be evident through accessibility to educative programs and instructional delivery like quiz, debate and so on. Productive situational delivery enhances learners' creative and intellectual development through the use of television images, graphics, audio, test motion for high quality learning. Babalola (2005) states that radio and television offers five distinct roles in education which are: Socialization, Religion, Subject, Brain test and Sex Education.

Educational television has been discovered to have profound effect on speech training among young learners (Gocen \& Okur, 2013). According to Gocen and Okur (2013) learners mimic what they see on television and as such remember more of the things they watch than the ones they learn in the classroom. Also, their study after studying the attitudes of 
students involved in the survey of effect of TV on speech, it is obvious that they do imitate how people talk on TV and thereby think that their friends will like them better that way. Also, students who took this survey point out that they like when their friends imitate TV characters.

One of television's most obvious characteristics is its visual aspect. Humans intuitively grasp the power of images to convey meaning, as can be seen in the old adage that values a picture at a thousand times the value of a word. Research in the past two decades has proven what we intuitively know: our brains deal with images differently than print (Saglik \& Ozturk, 2001). Words are processed in the neocortex where the higher thinking capability of the brain resides. Pictures, however, are handled in the limbic system, rapidly, and trigger instinct, emotion, and impulse (Omenesa, 1997). Because brains are programmed to remember experiences that have an emotional component, television has a powerful ability to relay experience through the emotions evoked by images.

Local Radio stations in Nigeria have specific programs aired to educate the audience on different contents related to Basic science and technology curriculum. For instance, the radio programs "'Abule Oloke Meje" and "Auto-maintenance" broadcasted from Ajilete 97.5 FM in Ogbomoso teaches the listeners about sexually transmitted diseases, community development and topics on several parts of a vehicle, the functions of the parts and how they can be maintained. Listeners are given ample opportunity to participate in the programs through phone calls. Likewise, the television program "Where there is no doctor" aired by Broadcasting Corporation of Oyo State (BCOS), Ibadan, teaches the listeners on various diseases and the causative micro-organisms. The program also enlightens viewers on sex education and effects of drug abuse.

Another local television station, Nigerian Television Authority (NTA) Ogbomoso airs a program that sensitizes the learners on their environment and how to preserve the environment. The program enlightens the listeners on pollution, different energy sources and their resultant effects on the environment. Similar programs that are educational can be accessed by students on satellite television stations like Learn-TV and Ed television on Multichoice cable also known as DSTV or Da-Vinci, NTA-Knowledge and BBC-Knowledge on Startimes cable television. Hence, this study intends to examine students awareness-of and utilization of educational broadcasts to learn in Ogbomoso, Oyo State.

\section{Importance of Educational Radio and Television}

Adediran (2004) states that radio and television offers five distinct roles which are: following as basic roles of radio and television in education:

$>$ Socialization: They help to socialize children on cultural values in their domain especially how to know about past, great personalities, ceremonies, dressing, and behavior. Through program like and some print contents dedicated to culture and education.

$>$ Religion: A lot are learnt today on radio and television about one's religion which presented by religion analysts, while religion leaders are invited to educate and sensitize their followers. Such programs carry titles like 'religion faith', 'time for paradise', 'words of God' est.

$>$ Subject: Various subjects like mathematics, English language, Yoruba and technological-based subjects are disseminated on radio and television to teach children. This can have titles like 'my TV teacher', 'TV education show', EST.

$>$ Brain Test: Children are also educated and tested through brain test competition shows such as TV quiz, who wants to be a millionaire, work it out, and so on.

$>$ Sex education: Sex education is presented to children on television and radio especially on how to protect themselves from unwanted pregnancy and diseases like HIV/AIDS, such as a radio program called Abule Oloke meje and many more. 
Educational radio and television are very important for several reasons. First, it helps in the delivery of quality educational programs to audience. Learners have the opportunity of listening or viewing relevant educational programs which indirectly enhance their understanding and stimulate their interest towards learning.

Second, it helps to increase access to formal education. Educational radio or television can offer a distance education secondary equivalency program for out-of- school youth and adults. Such people can thereafter register for internal final senior secondary school exams like NECO, WAEC or NABTEB in any school of their choice.

Third, educational radio and television programs help to support classes with under qualified teachers. It has been observed that most of the educational Radio or Television channels teach effectively and interestingly various secondary school subject topics. This has been particularly true in the science subjects where teachers are scarce. Fourth, educational radio or television programs expand the experiences of the children. For examples, in sciences, the programs can demonstrate many experiments that would not be possible to do in regular classrooms or even in laboratories. Thus, strengthens the teaching and learning process.

Effects of Educational Radio and Television on the Remembering Ability of the Students Previous studies revealed the positive impact of broadcast media (radio and television) on enhancing the achievement and performance of students and in gaining significant improvement changes in all areas (Kulik and Kulik, 1991; Kulik, 1994; Rutz, 2003; Baker, 1994). For instance, many studies of comprehensive effort investigated the impact of educational radio or television on secondary school students and reports show an increase in test scores by the students. Also, students gain more knowledge in less time because lessons become more enjoyable and interesting (Kulik, 1994).

Similarly, Sivin-Kachla (1998) found that students studying in a technology rich environment achieve higher marks in all subject areas, gain a positive attitude towards learning, are able to generate new ideas and build self- confidence. More so, Braun in 1990 indicated that educational media particularly radio and televisions improve students' motivation and attitudes about learning and also about themselves. Also, it increases students' attendance and decreases dropout rates. Preschool children who watched a few hours a week of educational programming perform better on achievement tests over time than their peers who watch more general entertainment shows (Huston \& Wright, 2014).

The researchers found that younger children, especially those aged 2 and 3, who watched a few hours a week of educational programs had higher scoring on academic tests 3 years later than children who did not watch the programs. Younger children who spent many hours watching entertainment programs had lower test scores than those who watched fewer hours. "Viewing of educational programming was associated with better school readiness and better academic skills," Huston noted. "Watching educational television may be an important vehicle for children to get some early learning that can really make a positive contribution." Huston notes that she and her colleagues took into account possible influences such as the family's level of education and socioeconomic factors. Empirically, radio and television are capable of delivering high quality educational program to highly diversified audience located across broad geographical expanses-all at a low per unit production cost (couch, 1997). Also, United Kingdom Universities have demonstrated that when used as supplementary learning tools, they benefit weaker students (Tripp and Roby, 1996). The Agency for International Development has shown educational radio and television to be more cost effective and capable of exerting greater learning effect on secondary school students than textbook or teacher education (Tripp and Roby 1996).

Furthermore, Zanguyi (2011) showed that teachers' attitudes towards new educational technologies such as radio and television in process were positive. Similarly, Dogruer, 
Eyyam and Menevis (2010) found that teachers agreed that the educational radio or television has a positive impact on their experience. In the same way, Ozcinar, Hursen, Ozdamli (2009) observed that teacher trainees believed in positive effects of educational radio and television. More so, educational radio and television can provide instruction for one group of students whilst the teacher is occupied with another. As a medium that can be listened to in the privacy of one's home or room, they are often the preferred choice for those seeking information on culturally taboo topics such as HIV/AIDS or STDS.

Jaminson and MC Anancy (1978) report four main advantages of educational radio and television: improve education quality and relevance; lower per student educational costs; Improve access to education particularly for disadvantaged students or groups and ; It provides a crystal clear audio and visual signal, which is particularly important in instructional programs. Therefore, the broadcast media (radio and television) remain a channel that had proven educational worth in terms of both pedagogical importance and geographical reach.

Interactive radio instruction (IRI) consists of broadcasting lessons to audience on a daily basis, on a particular topic and aimed at specific level. It provides regular structure assistance to teachers and serves to improve the quality of teachers and serves to improve the quality of teaching and enhance learning. IRI also serves to expand access to education, by bringing ready-made lessons to remote schools and learning centers which have few resources and teachers. It is also a cost-effective means of delivering educational content to a large number of people.

Television lessons can be used to supplement other course materials or can be stand-alone lessons. Such lessons have progressed over the years from simply being television programs showing teachers talking, to being more engaging and interactive programs which incorporate issues relevant to the learners. Educational television programs are often accompanied by printed materials and other resources to enhance learning and interaction. These are mostly practiced in advance country or any civilized world.

More so, educational broadcasting, aside from being used for broadcasting specific lessons, radio and television can be used to broadcast general educational programs. Basically, any radio or television program with educational value can be considered a 'general educational program'. While general educational programming consists of a broad range of program types - news programs, documentary programs, quiz shows, educational cartoons est., that afford non-formal educational opportunities for all types of learners. In a sense, any radio or television program with informational and educational values can be considered under this type.

\section{Statement of the Problem}

Basic Technology as a subject has been affected by the use of information and communication technologies which radio and television are key components of and this have undoubtedly affected the teaching and learning of the subject (Yusuf, 2005). The reason for this could be ascribed to the fact that there are topics in basic technology that pose serious problem of comprehension to students. These topics cannot be taught effectively without the use of relevant channel/media such as broadcast media (radio or television) which provides not only audio or audio-visual images but also make learning practical and interesting.

Radio and television are already playing a role in educating the populace non- formally, but there is significant potential to capitalize on the ability of the broadcast media to enhance development and learning among secondary school students. Their use in education have the potential to innovate, accelerate, enrich, and deepen skills, to motivate and engage students, to help relate school experience to work practices, create economic viability for tomorrow's workers, as well as strengthening teaching and helping schools change (Davis and Tearle, 1999). Therefore, this research examined the effectiveness of educational radio and television on learning basic science and technology. 


\section{Research Questions}

$>$ Are secondary school students in Ogbomoso aware of educational radio and television programs around them?

$>$ Do secondary school students in Ogbomoso have access to educational radio and television programs?

$>$ What are the problems militating against students' use of educational radio and television for learning?

\section{METHODOLOGY}

This study was a descriptive research of survey type. It is meant to ensure that the evidence obtained enables this research to answer the research questions as unambiguously as possible. This study ascertained the status quo of secondary school students' awarenessof and use-of educational broadcasts for learning purposes. Questionnaire was utilized as instrument for the study to enable the researcher gather responses from a reasonably large number of secondary school students in Ogbomoso.

\section{Participants}

The population for this study were all students in secondary schools in Ogbomoso. The target population for the study constitutes the students of junior secondary school in five selected public secondary schools in Ogbomoso randomly selected through ballot system. 20 students were taken from each selected secondary school. It should be noted that a total of one hundred (100) respondents constitute the sample element. Therefore, one hundred questionnaires were administered to the students to obtain data for the study.

\section{Research Instrument}

Researcher designed questionnaires tagged "Students Awareness-of and Utilization of Educational Broadcasts to Learn Questionnaire (SAUEBLQ)" was distributed among respondents. It was constructed after a careful and extensive study of the related literature. The questionnaire was divided into four sections (A to $D)$. Section ' $A$ ' contains background information which requires each respondent to indicate the gender and class. Section ' $B$ ' of the instrument required the students to indicate their awareness of listed educational radio and television programs and also indicate whether they have access to the programs or not. Section ' $C$ ' requires the students to indicate the extent to which they agree or disagree with the statements that listed problems militating against students' use of educational television and radio to learn. The instrument was validated by experts from the field of Educational Technology at the University of Ilorin to check the instruments appropriateness to measure what it was intended to measure and how adequately it was going to measure it. Wording problems, ambiguity and sentence structure of the questionnaire were improved following the suggestions of these experts.

\section{Data Collection and Analysis}

The consent of the school authorities whose students formed the sample for the study was obtained to administer the questionnaire to the respondents. The administration of questionnaires was done with the assistance of the school teachers and responses were collected immediately from each of the selected secondary schools. The researcher explained the purpose of the questionnaire to respondents as well as emphasizing the importance of their responses and assured them that their responses would be kept confidential and used solely for the purpose of this research. Data collected for this study were analyzed using simple percentages and means

\section{FINDINGS AND DISCUSSIONS}

Table 1 shows the awareness of secondary school students on educational television and radio programs in Ogbomoso. The analysis shows that generally students in Ogbomoso were not aware of educational television and radio programs available to them with a mass response of $63 \%$. 
Table 1. Awareness of Secondary School Students on Educational Television and Radio Programs

\begin{tabular}{lllll}
\hline S. No. & Programme & Station & $\%$ Yes & $\%$ No \\
\hline 1 & Abule Oloke Meje & Ajilete FM & 26 & 74 \\
2 & When there is no doctor & BCOS, Ibadan & 57 & 43 \\
3 & You and Environment & NTA, Ogbomoso & 63 & 37 \\
4 & Sex Education & Learn TV (DSTV) & 40 & 60 \\
5 & Technology and Energy around us & Da-Vinci (Startimes) & 32 & 68 \\
6 & $\mathbf{2 1}$ st Century Innovations & BBC Knowledge & 25 & 75 \\
7 & Basic Science and Technology & Ed television (DSTV) & 15 & 85 \\
& & Average \% & 37 & 63 \\
\hline
\end{tabular}

The findings have strong implications on the mass media or distance teaching and learning process especially in secondary schools in Oyo State. The finding that majority of the secondary school students in Ogbomoso town in Oyo State were not aware of the educational television and radio programmes around them is an indication that there are still lots of grounds to cover with regards to educational broadcasting in the state. There is need to sensitise the students to tune in to particular programmes that would benefit them academically. The teachers and producers that air such programmes also need to visit schools to intimate the students about such programmes. Likewise, this finding suggest that students in Ogbomoso were more aware of contents on local channels (BCOS and Ajilete FM) than those on the satellite cable dishes (Startimes and DSTV).

Overall, Table 1 shows that majority of the secondary school students in Ogbomoso were not aware of the educational television and radio programmes around them with an average percentage of $63 \%$ and only $37 \%$ of the students were aware of educational television and radio programmes around them. This finding is in tandem with that of Familusi and Owoeye(2014) who showed that residents of Ekiti (another town in Nigeria) utilises radio broadcast majorly for entertainment and current affairs purposes. However, This finding is in contrast to that of Akhter (2011) who revealed that students in Pakistan showed mass awareness of educational television programmes(ETV) for effective distance learning. Majority (92\%) of these distance learners were aware about the ETV programs. This difference in the findings could be because the study in Pakistan was conducted on University students.

Table 2 shows the secondary school students access to educational radio and television programmes in Ogbomoso. It indicates that majority of the secondary school students in Ogbomoso can access educational television and radio programmes around them with an average percentage of $68 \%$ and only $31 \%$ of the students indicated that they do not have access to the educational television and radio programmes around them.

Table 2. Secondary School Students Access to Educational Radio and Television Programs in Ogbomoso

\begin{tabular}{lllll}
\hline S. No. & Programme & Station & $\%$ Yes & $\%$ No \\
\hline 1 & "Abule Oloke Meje" & Ajilete FM & 92 & 8 \\
2 & When there is no doctor & BCOS, Ibadan & 73 & 27 \\
3 & You and Environment & NTA, Ogbomoso & $\mathbf{8 7}$ & 13 \\
4 & Sex Education & Learn TV (DSTV) & 54 & 46 \\
5 & Technology and Energy around us & Da-Vinci (Startimes) & 61 & 39 \\
6 & $\mathbf{2 1}$ st Century Innovations & BBC Knowledge & 61 & 39 \\
7 & Basic Science and Technology & Ed television (DSTV) & 54 & 46 \\
& & Average \% & 68 & 31 \\
\hline
\end{tabular}


Another finding of this study revealed that majority of the secondary school students in Ogbomoso can access educational television and radio programs around them. This shows that if proper sensitization is done and students are aware of the programs, there is no problem in accessing the programs with personal radio and television sets. This implies that secondary school students in Ogbomoso have access to functional radio and television sets that is connected to the radio and television stations that transmits educational programs. This is in line with the study of Familusi and Owoeye (2014), a research on use of radio and other means of information dissemination by the residents of Ado- Ekiti, Ekiti-State, Nigeria, which showed that the populace have good access to radio and television sets for receiving programmes.

Table 3 shows the analysis of respondents' opinions about the possible problems that militate against students' use of educational radio and television to learn in Ogbomoso, Oyo State.

Table 3. Problems Militating against Students' Use of Educational Radio and Television for Learning

\begin{tabular}{lllc}
\hline S. N & & Major Constraints & Mean \\
\hline 1 & $\begin{array}{l}\text { Inadequate power supply to use the television and radio to access educational } \\
\text { broadcast }\end{array}$ & 3.20 \\
2 & High cost of subscriptions to the satellite television stations (Startimes and DSTV) & 2.96 \\
3 & Inconvenient time of airing educational broadcasts on the television stations & 3.09 \\
4 & Educational broadcasts are usually not interesting to listen-to or watch. & 2.88 \\
5 & High cost of acquiring television and radio sets & 2.41 \\
& & Grand Mean & 2.91 \\
\hline
\end{tabular}

Table 3 shows the analysis of respondents' opinions about the possible problems that militate against students' use of educational radio and television to learn basic technology in Ogbomoso, Oyo State. The table shows that "Inadequate power supply to use the television and radio to access educational broadcast" is considered the most prominent mitigating factor with mean score of 3.20. This is closely followed by "Inconvenient time of airing educational broadcasts on the television stations" with a mean score of 3.09. The respondents also consider "High cost of subscriptions to the satellite television stations (Startimes and DSTV)" and "Educational broadcasts are usually not interesting to listen-to or watch" as strong mitigants towards the use of educational television and radio programs for learning with mean scores of 2.96 and 2.88 . However, the respondents do not consider "high cost of acquiring television and radio sets" an issue that could mitigate the use of educational television and radio programs for learning basic technology with the item scoring a mean score of $\mathbf{2 . 4 1}$ which is lower than the benchmark score of 2.5 of 4 point Likert-scale used for data gathering. Overall, secondary school students in Ogbomoso town considered the items checked as real problems mitigating use of educational television and radio programs to learn basic technology with a grand mean score of 2.91 .

The study further revealed that the cost of accessing learning on satellite television stations through DSTV and Startimes cable are expensive and this corroborates the findings of Familusi and Owoeye (2014) who revealed that the cost of accessing information on radio, television and use of mobile phone is not expensive while that of internet access and paying subscription to DSTV and other cable television is expensive. On the most affordable and 
usable media in providing access to information for agricultural purposes, Kakade (2013) revealed radio is the most accessible and usable in accessing information by the farmers followed by mobile phone, television and newspaper. Kakade (2013) report showed that social network, DSTV, cable television and internet are expensive for the rural farmers to access agricultural information.

\section{CONCLUSIONS AND RECOMMENDATION}

This research examined effect of educational radio and television services on learning of basic technology in Ogbomoso, Oyo State and concluded through thorough data analysis that Secondary school students in Ogbomoso have ample access to educational radio and television broadcasts but they are uninformed about educational programs existence and timing. Also, the study concluded that secondary school students have several factors that bar them from utilizing educational broadcasts to learn, all of which could be surmounted if adequate publicity is given to the educational programs to increase students' awareness of the programs.

Based on the findings and conclusions of this study, the following recommendations were made:

$>$ Educational programs producers on both radio and television should create enough awareness about the programs to enable students follow the programs at appropriate time.

$>$ Pricing of subscription charges for satellite channels that transmits educational broadcasts should be regulated or subsidized by the government to allow equal opportunities for all students irrespective of socio economic status of parents or guardians.

$>$ Adequate planning and entertainment should be packaged into educational broadcasts to motivate learners to follow such programs.

$>$ Teachers in secondary schools should include educational broadcasts as forms of stimulus variation that they could applied to their classes.

$>$ Curriculum planners and professional associations like Teachers Registration Council of Nigeria(TRCN), Nigeria Union of Teachers (NUT), Parent Teachers Association (PTA), Social Studies Educationist Association of Nigeria (SOSAN) should encourage their members - the administrators of schools and the secondary school teachers to utilize radio and television channels at disseminating knowledge to the learners

$>$ Students should be encouraged to tune in to educational programs on their radio and television sets notwithstanding various distractions of entertainment channels.

\section{BIODATA and CONTACT ADDRESSES of AUTHORS}

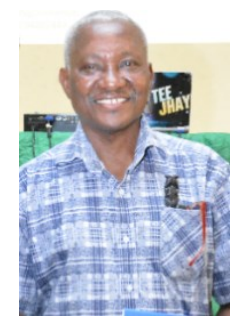

Charles Olubode OLUMORIN is a Senior Lecturer in the Department of Educational Technology, Faculty of Education, University of Ilorin, Ilorin Nigeria. Dr. Olumorin had his Ph.D. in Educational Technology in the year 2009. His area of interest are Instructional Technology and Distance Learning. Olumorin has published over 30 journal Articles in National and International outlets. He has 4 chapters in reputable books. He regularly attend conferences nationally and internationally. 
Charles Olubode OLUMORIN

Department of Educational Technology, Faculty of Education

University of Ilorin, Ilorin, Nigeria.

Phone: $\mathbf{2 3 4 8 0 6 6 4 9 4 9 7 9}$

E-mail: bodeolumorin@unilorin.edu.ng

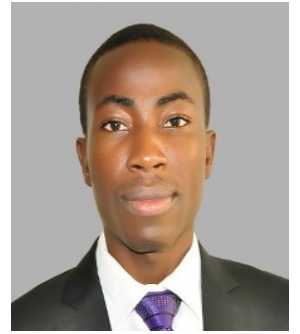

Adekola Musiliu ADEROJU is an Assistant Lecturer and a Doctoral Student in the Department of Educational Technology, University of Ilorin, Nigeria. He completed his Masters Degree in 2016. He has keen interest and continues to work in the field of Open and Distance Learning, Mobile Learning, Massive Open Online Courses, Personal Learning Environments, E-Learning Systems, Instructional Technology, Classroom Enrichments, and Computer Based Tests. He has written and published articles and studies in different areas of Educational Technology in different journals.

Musiliu Adekola ADEROJU

Department of Educational Technology

Faculty of Education, University of Ilorin, Ilorin, Nigeria

Phone: +2348058054962

E-mail: kolaroju@gmail.edu.ng

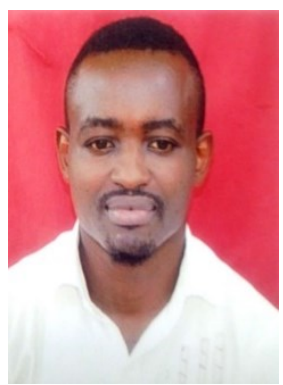

Amos Ochayi ONOJAH is a Ph.D student of E-learning at the department of educational technology, Faculty of Education, University of Ilorin, Nigeria. Mr. Amos Ochayi ONOJAH gained his masters in Educational Technology at December, 2016. His academic interest areas are innovative technologies, learning analytics, social network analysis, educational hypermedia and multimedia, educational interfaces, education futures, e-learning, Blended learning, learning applications cyber behaviors and use of technologies in education. He has over than 3 journal articles published in international indexes, and other national and international articles, papers submitted to international meetings.

Amos Ochayi ONOJAH

Department of Educational Technology, Faculty of Education

University of Ilorin, PMB 1515, Ilorin, Nigeria

Phone: +2348035567585

E-mail: haymoresonojah@yahoo.com

\section{REFERENCES}

Agbo, S. I. (2015). Factors influencing the use of information and communication technology in teaching and learning computer studies in Ohaukwu Local Govt. Area Ebonyi State. Journal of Education and Practise, 6(7), 71-86.

Akhter , N. (2011). Evaluation of educational television programmes for distance learning. The Turkish Online Journal of Educational Technology, 10(4), 188-194.

Babalola, B. K. (2005). A Guide to Educational Technology. In Kolade-Oje, O. T. And Babalola, S. K. (eds). Ado-Ekiti: Tomol Publishers.

Berman , S. D. (2008). The Return of Educational Radio? Canada: MDE Programme, Athabasca University.

Charles, P. A. (2014). ICT Competence and Lecturers' Job Efficacy in Universities in Cross River State, Nigeria. International Journal of Humanities and Social Science, 4(10), 259-266.

Familusi, E. B., \& Owoeye , P. O. (2014). An assessment of the use of radio and other means of information dissemination by the residents of Ado- Ekiti, Ekiti-State, Nigeria. Library Philosophy and Practice (e-journal), 1-29. Retrieved April 14, 2017, from http://digitalcommons.unl.edu/libphilprac/1088 
Gocen, G., \& Okur, A. (2013). The effects of TV on speech education. Educational Research and Reviews, 8(2), 63-68.

Kakade, Onkargouda (2013) Credibility of Radio Programmes in the Dissemination of Agricultural Information: A Case Study of Air Dharwad Karnataka,IOSR. Journal of Humanities Social Science (10SR-JHSS) Vol.12, Issue 3 pp18-22. www.losrjournal.org.

Omenesa Z.E. (1997) Rural agricultural radio in Nigeria. An overview of the National Agricultural Extension and Research Liaison Service (NAERLS) Farm Broadcaster. J. Agric Ext. pp. 74-81.

Onabajo, O. (2000). Principles of Educational Broadcasting. Gabi Concepts Limited. Lagos.

Ortyoyande, J.H. (2006). The implementation of teacher education programme in Nigeria. Journal of Education and Vocational Studies. 1(4), 24-40

Saglik, Mediha \& Ozturk, Serap (2001) Television as an Educational Technology: Using Television At Open Education Faculty, Anadolu University. Turkish Online Journal of Distance Education-TOJDE. 2 (1) 6-21 retrieved from https: //tojde.anadolu.edu.tr/tojde3/pdf/6.pdf

Sambo, M.H. (2012). Assessment of the implementation of Basic Science programme in Junior Secondary Schools in Nasarawa State. A PhD Thesis University of Agriculture, Makurdi. Benue State-Nigeria

Wright, J. C, Huston A., Murphy K., Peters, M., Pinon, M., Scantlin, R. \& Kottler J., (2011) The relations of early television viewing to school readiness and vocabulary of children from low-income families: The early window project. Journal of Child Development, 72 (5) 1347-1366 